\title{
LUAMANDA E SUAS “SETE FACES”: UM OLHAR SOBRE O CONTO “LUAMANDA” DE CONCEIÇÃO EVARISTO
}

\author{
Fernanda de Quadros Carvalho Mendonça* \\ Adriana Maria Abreu de Barbosa*
}

RESUMO: O conto Luamanda, que compõe o livro Olhos D'agua (2016), da escritora Conceição Evaristo, suscitou a reflexão sobre as representações das identidades femininas que permeiam a cultura patriarcal, dessa vez tendo como voz autoral uma escritora negra. Não está sendo fácil viver a pós-modernidade no Brasil, dessa maneira precisamos recorrer à literatura e à crítica literária em busca de um lenitivo. Se tomarmos a Literatura como um lócus de tecnologia de gênero (espaço no qual mulheres são criadas) e nos propusermos a fazer leituras feministas de textos literários, reconheceremos que há necessidade e urgência da apropriação pelas mulheres do feminismo e suas bandeiras. Isto é, este ensaio reconhece a importância do Feminismo como uma escola do pensamento que nos ensina um modo de ver o mundo. Portanto, a nossa proposta de leitura vê na narrativa das experiências amorosas da protagonista Luamanda as "sete faces" de uma mesma mulher, mostrando, por meio das experiências vividas e revisitadas (escrevivências), a composição e a construção de uma mulheridade. Objetivamos, assim, com este ensaio, à luz da crítica feminista, desvendar quantas mulheres há em Luamanda.

PALAVRAS-CHAVE: Literatura. Mulher(es). Feminismo(s). Identidade feminina.

\footnotetext{
* Mestranda do Programa de Pós-Graduação em Letras: Cultura, Educação e Linguagens (PPGCel). Bolsista da Fundação de Amparo à Pesquisa do Estado da Bahia (Fapesb).

${ }^{* *}$ Doutora em Letras pela Universidade Federal do Rio de Janeiro (UFRJ). Pós-doutora em Letras pela Universidade Federal de Pernambuco (UFPE). Professora do Programa de Pós-Graduação em Letras: Cultura, Educação e Linguagens (PPGCel) da Universidade Estadual do Sudoeste da Bahia (Uesb).
} 


\section{Feminismo: uma descoberta que ainda precisa ser feita...}

O modernismo trouxe para a sociedade brasileira muitos avanços democráticos que nos deram a sensação de que alguns problemas, como racismo, homofobia, fascismo, seriam resolvidos através da liberdade e respeito entre os indivíduos. Ledo engano. Precisamos de utopia para viver, e hoje, no Brasil do século XXI, o feminismo ainda precisa ser descoberto pelas mulheres e ser para elas a sua utopia (combustível para sobreviver ao prenúncio de tempos sombrios). Concordamos com Woolf, quando ela afirma que: “[...] ainda vai levar muito tempo até que uma mulher possa se sentar e escrever um livro sem encontrar com um fantasma que precise matar, uma rocha que precise enfrentar" (WOOLF, 2013, p. 17).

Isto posto, precisamos destacar que nós, mulheres, diariamente, somos solicitadas a nos posicionar no mundo, o que torna urgente a apropriação da nossa história e identidade, por intermédio do conhecimento do movimento feminista e de sua atuação nos dias de hoje. Conforme salienta Silva (2019) “o despertar da consciência individual parece ser o principal campo de modificação e de mobilização do ser”. Silva (2019) sinaliza ainda que ter a "arte como mecanismo de educação de um povo pode proporcionar contestações, desmitificações e intercambiar vozes femininas e masculinas que pretendem um outro mundo possível". Acreditamos que esse despertar, apesar de individual, busca um coletivo, e que através do conhecimento do feminismo(s) e da literatura poderá ser um caminho para resistir a esse tempo em que vivemos.

Na década de noventa, Muraro (2003) escreveu que um novo mundo estava em gestação, verificamos nesse escrito uma dose de otimismo devido aos avanços dos processos democráticos no caminhar para o novo século. Contudo, refletindo sobre os dias atuais, sem ignorar os grandes avanços obtidos pela luta feminista, estamos vivenciando um período em que, pelo processo democrático, movimentos conservadores têm ganhado voz e vem questionando mais uma vez a efetividade política da luta das mulheres e seus direitos. Ainda hoje, em pleno século XXI, declarar-se feminista soa como uma afronta, e até corremos o risco de sermos ridicularizadas pela declaração. O machismo impera em nossa 
sociedade e vivemos um governo que legitima essas práticas. Assim, Adichie (2015) nos alerta para as dificuldades decorrentes de termos nossas condutas baseadas tão somente nas questões de gênero. Ela nos informa que "o problema da questão de gênero é que ela prescreve como devemos ser em vez de reconhecer como somos" (ADICHIE, 2015, p. 36). Vivenciamos o avanço de discursos que deslegitimam a importância da luta feminista e, por isso, é preciso escutar as vozes das autoras que lutam pela causa.

Hoje se fala, acertadamente, em feminismos. Para nós, o marco desta filosofia é a publicação da obra Segundo Sexo, de Simone Beauvoir (1960a, 1960b), um tratado filosófico sobre os ditames do Patriarcado sobre o mundo das mulheres

O patriarcalismo é um sistema de organização social caracterizado pelo poder de um patriarca. Estima-se que a propriedade privada, causa da hierarquia de classes, assim como as sociedades escravagistas, operam com a lógica da dominação, sob a qual um patriarca exerce poder sobre mulheres reconhecidas como posses. A dominação também se deu pelo aniquilamento simbólico das mulheres. No cânone literário, operou-se esse aniquilamento seja pela negação às mulheres de fazerem literatura, seja pela forma como eram retratadas por autores homens (BONNICI, 2007).

Todavia, interessa-nos, embora reconhecendo a necessidade das especialidades apontadas por várias vertentes do feminismo contemporâneo, o que esses feminismos têm em comum como uma escola de pensamento que ganhou espaço no mundo científicoacadêmico na entrada do século XX e sentou-se à mesa da filosofia, antes território do masculino. Sobre o que nos une e identifica em meio nossa diversidade, adotamos a definição de Margareth Rago (2013):

Considero os feminismos como linguagens que não se restringem aos movimentos organizados que se autodenominam feministas, mas que se referem às práticas sociais, culturais, políticas e linguísticas que atuam no sentido de libertar as mulheres de uma cultura misógina, e da imposição de um modo de ser ditado pela lógica masculina nos marcos da heterossexualidade compulsória (RAGO, 2013, p. 28). 
Isto é, o tornar-se mulher anunciado em Beauvoir ([1949]1960a,1960b) nos livra de uma determinação meramente biológica e estende-se ao que Lauretis (1987) chama tecnologias de gênero. As mulheres são produtos de uma cultura, elas são o resultado, dentre outras coisas, do que a arte diz sobre elas e até mesmo do que os feminismos dizem sobre elas. Descoberto isso, dizer-se passou a ser o desejo das escritoras. Pela autoficção, pelo trabalho com a memória individual e coletiva, pelas escrevivências, elas ousaram dizeremse, e nós, em escuta crítica, somos todos ouvidos.

Com base nesse cenário teórico-filosófico, este ensaio propõe desvendar o conto Luamanda à luz da crítica feminina. Corrente teórica que nos permite compreender que reconhecer as diversas mulheres existentes em Luamanda significa adotar a perspectiva atual de que somos muitas e distintas, mas lutamos por uma causa comum: a igualdade de gêneros. Ao tempo que afirmamos que somos diferentes, mas não precisamos ser desiguais.

Barbosa (2011) destaca que a crítica feminista, independente da orientação, visa à criação de seus próprios critérios de leitura, um reconhecimento à cultura feminina, permitindo a interpretação de uma obra pelo olhar de uma mulher.

Portanto, o feminismo do qual falamos, atualmente, reconhece que temos um problema de gênero, por isso requisita uma revisita às nossas origens para ressignificar o presente e o futuro e nos cobra uma nova forma de estar no mundo, assim como faz tão bem Luamanda em suas cinco décadas de "vida-estrada".

\section{Vida e Obra da escritora Conceição Evaristo}

$\mathrm{Na}$ sociedade brasileira patriarcal, cabe à literatura feita por mulheres reconstruir o papel social da mulher, mais ainda da mulher negra, que, além de sofrer o preconceito de gênero, sofre o preconceito de cor e teve sua imagem e representação social sempre associada às figuras que viviam à margem da sociedade, com descrição de papéis na literatura de pouco prestígio social. Dentro dessa realidade literária, a escrita de Conceição Evaristo surge como uma nova voz, mas não em relação à recepção, pois já há outras escritoras negras na história da literatura brasileira. 
A obra de Evaristo é relevante por apontar a luta diária das mulheres negras, sua condição social na sociedade brasileira e por propor a reconstrução e ressignificação da identidade feminina por meio de suas personagens. Evaristo utiliza da escrita de suas escrevivências para desfazer os estereótipos construídos pelo patriarcado. A autora salienta que seu fazer literário, a sua escrevivência, "não pode ser lida como histórias de ninar os da casa grande e sim incomodá-los em seus sonos injustos”, ressaltando que este é um dos propósitos da sua escrita (EVARISTO, 2007, p. 21).

$\mathrm{Na}$ escrita de Evaristo, desde as primeiras publicações de seus contos nos Cadernos negros (1995), há a denúncia da violência instalada no Brasil. Segundo Silva (2018), “décadas se passaram e tais questões ainda continuam como cancro social, visto o alto índice dos mais variados tipos de violências, principalmente os feminicídios que assolam o país em pleno século XXI, contextualizado no início deste artigo”. (SILVA, 2018, p. 66-67)

Veremos nos textos de Evaristo e em seus personagens a "escrevivência" com o papel de reescrever a história do povo negro brasileiro. Cortês (2016) destaca que o conceito tem o objetivo de trazer um diferente olhar para a cena literária habitual.

A escrevivência para Evaristo é a escrita de um corpo, de uma condição, de uma experiência negra no Brasil (EVARISTO, 2007, p. 20).

Côrtes (2016) nos propõe, ainda, que “a palavra escrevivência é um neologismo que, por uma questão morfológica, facilmente compreendemos do que se trata e que Evaristo se apropria do termo para elucidar seu fazer poético" (CÔRTES, 2016, p. 52).

Evaristo, ao inaugurar o termo e fazer dele fio condutor que tece seus textos, abre espaço para que autoras dessa geração, também negras, o utilizem para trazer para o texto literário toda a vivência de seus corpos marcados pelas experiências sofridas em nossa sociedade. Para Santiago (2019) "a produção literária de mulheres negras brasileiras tem se configurado como uma gramática literária atravessada por temas que desfilam entre anseios por transformações e ressignificações de (re)existências e por fios históricos, imaginários e existenciais que tecem, descontínua e paulatinamente, suas tessituras literárias" (SANTIAGO, 2019, p. 15). 
Santiago (2019) nos alerta sobre a necessidade de compreensão "da produção literária de autoras negras como um projeto integrante da literatura brasileira, através do qual se gestam palavras e narrativas (en) cantadas, comprometidas, não tão somente com a fruição, mas também com modos criativos e discursivos de mobilização de existências". (SANTIAGO, 2019, p. 12) Sendo a literatura, o fazer literário, um campo de luta contra o apagamento identitário sofrido por essas mulheres.

A escritora Maria da Conceição Evaristo de Brito nasceu em Belo Horizonte, em 1946. Na década de 1970 migrou para o Rio de Janeiro, cidade em que mais tarde veio a se graduar em Letras pela UFRJ. Quando formada, trabalhou como professora da rede pública de ensino da capital fluminense. Tornou-se mestre em Literatura Brasileira pela Pontifícia Universidade Católica do Rio de Janeiro (PUC-RJ) e doutora em Literatura Comparada pela Universidade Federal Fluminense (UFF). A sua estreia como escritora foi em 1990, na série Cadernos Negros, do grupo Quilombhoje, coletivo de escritores afro-brasileiros de São Paulo. Encontramos na sua biografia o romance Ponciá Vicêncio (2003), o romance Becos da memória (2006), poesias publicadas em antologias, o livro de poemas Poemas de recordação e outros movimentos (2008), livro de contos Insubmissas lágrimas de mulheres (2011), o livro Olhos D’água (2015), ganhador do Prêmio Jabuti na categoria “Contos e Crônicas”, o livro Histórias de leves enganos e parecenças (2017). Em 2017, o Itaú Cultural de São Paulo realizou a Ocupação Conceição Evaristo contando sua vida e expondo sua obra. No ano de 2018, foi candidata a uma cadeira na Academia Brasileira de Letras, fato que trouxe maior visibilidade ao seu trabalho devido a uma grande campanha para a sua eleição. Nesse mesmo ano, a escritora recebeu, também, o Prêmio de Literatura do Governo de Minas Gerais pelo conjunto de sua obra e foi a escritora homenageada de duas feiras literárias, a saber: a III Feira Literária de Mucugê Bahia (FLIGÊ) e Festa Internacional Literária de Cachoeira - Bahia (FLICA). Finalizou o ano de 2018 com o seu mais novo livro, a novela Canção para Ninar Menino Grande, pela editora Unipalmares, que traz um homem como personagem principal. 
"Luamanda" se encontra no livro de contos Olhos D'agua. O livro contém uma coletânea de contos escritos entre os anos 1990 e 2010. Numa entrevista sobre a obra, Evaristo destaca que dos quinze contos publicados no livro supracitado, apenas quatro são lançamentos: Os amores de Kimbá, Luamanda, O cooper de Cida e A gente combinamos de não morrer, pois os demais já haviam sido publicados anteriormente, nos Cadernos Negros, que traz a produção literária afro-brasileira desde 1978 organizada pela editora Quilombhoje.

\section{Luamanda e suas "sete faces"}

Luamanda é a personagem principal do conto que tem o seu nome. Nele encontraremos a história do aprendizado de ser e tornar-se mulher, a descoberta do seu estar no mundo, assim como é proposto pelo(s) feminismo(s) atual(ais). A história é uma narrativa do reconhecimento e crescimento como mulher, mediante as relações amorosas experienciadas ao longo de cinco décadas.

Em Luamanda, existem "sete faces" de uma mesma mulher, ou melhor, mulheres distintas que se encontram numa só. Espontaneamente, podemos fazer uma alusão ao poema, "Sete Faces" de Drummond, que conta a trajetória de Carlos em sete estrofes, já que cá a história amorosa de Luamanda apresenta "sete faces" de uma mulher, como assinala, em um dado momento do texto, o narrador, no trecho em que sugere: ' $[$.... Luamanda, a avó, mãe, amiga, companheira, amante, alma-menina no tempo” (EVARISTO, 2016, p. 63).

Permita-nos por um instante uma pequena digressão. Chegamos a Drummond pelas pistas da autora que se mostra uma leitora da literatura modernista no Brasil. Contudo, Conceição utiliza o recurso da intertextualidade para mencionar o poema retrato de Cecília Meireles, comparando Luamanda a outra voz feminina já canônica:

Encarou novamente o espelho e se lembrou de um poema, em que uma mulher, contemplando a sua imagem refletida, perguntava angustiada onde é que ela deixara a sua outra face, a antiga, pois não se reconhecia naquela que lhe estava sendo apresentada naquele momento (EVARISTO, 2016, p. 63). 
Se o tempo é melancólico em Cecília, um tempo histórico, no qual escritoras precisavam se enquadrar para caber na literatura canônica, o tempo em Conceição acena novas possibilidades de vivências e esperanças.

Ademais, num campo discursivo literário que remete à literatura brasileira moderna e contemporânea, se lembramos de Drummond e suas sete faces emparedadas do anjo torto, com menos possibilidades também que Luamanda, não poderíamos deixar de mencionar Adélia Prado que com Licença Poética responde ao poeta, inaugurando linhagens: a das mulheres escritoras na literatura brasileira. Alguns anos depois de Adélia (1976), precisamente vinte seis anos, em 1990, surge Conceição Evaristo, das margens e da periferia, deixando-nos ouvir vozes há muito silenciadas. Em especial, nesse conto, entre dores e denúncias, há lampejos de esperança.

A personagem principal é apresentada através das suas relações amorosas com outros personagens ao passar das cinco décadas. Inicia com a reflexão da Luamanda, aos cinquenta anos, questionando o amor, prossegue com a descoberta do amor pela menina, depois do amor adolescente, o amor de mãe, de uma mulher por outra, do amor por um homem mais jovem, o amor por um homem mais velho e o amor trágico.

No primeiro momento, Luamanda encontra-se no presente relembrando o passado, permitindo que a experiência da sua idade ressignifique suas vivências. Importante ressaltar que esta é uma das propostas que o feminismo vem assumindo. No trecho destacado a seguir, Luamanda questiona se amar ainda é possível na sua idade.

[... Havia dias em que era tomada de uma nostalgia intensa. Era a lua mostrar-se redonda no céu, Luamanda na terra se desminlinguia todinha. Era como se algo derretesse no interior dela e ficasse gotejando bem na altura do coração. Levava a mão ao peito e sentia a pulsação da vida desenfreada, louca. Taquicardia. Tardio seria, ou mesmo haveria um tempo em que as necessidades do amor seriam todas saciadas? (EVARISTO, 2016, p. 59-60, grifo nosso)

Logo em seguida, o narrador nos apresenta a primeira mulher, a menina de 11 anos. Esta, ele conta, iniciara muito cedo a busca pelo amor. Um amor de escolar, conforme podemos inferir pelos elementos apresentados no texto ("revistas em quadrinhos", "giz de 
cera colorido" e "pão com salame") e marcado por uma surra dada pela mãe. A menina teve a sua primeira experiência marcada pela dor, assim associou que a "a dor de amor era tanta, porque tinha 11 anos e um corpo-coração pequeno" e quis crescer (EVARISTO, 2016, p. 60).

A segunda mulher é uma adolescente de 13 anos que perde a sua virgindade em um terreno baldio com um menino também virgem. Ao relatar essa experiência, a autora utiliza termos como "corpo-coração", "gozo-dor", que servem para ilustrar a construção da identidade dessa mulher que está crescendo com suas vivências amorosas. Luamanda se fez mulher ao ser iniciada sexualmente, assim como o menino se fez homem, aqui temos um relato de igualdade entre os desiguais. Uma experiência que para Luamanda, apesar da dor de ter seu "corpo-coração espetado por um falo", foi associada a um terremoto, quando vimos no texto ela questionar: “o amor é terremoto?” (EVARISTO, 2016, p. 60).

A terceira mulher que encontramos no conto é uma mulher que, após ter acumulado várias vivências amorosas, irá experienciar a maternidade, ao encontrar um amor à primeira vista. A sua maternidade é guiada pela lua que demarcava o tempo da gravidez e o nascimento das crianças. Luamanda teve 5 filhos desse homem que navegou no "buracocéu aberto de seu corpo", descobrindo e entregando-se aos mistérios amorosos. Veremos aqui uma mulher conectada à natureza, numa relação baseada no respeito ao seu corpo, na lua que rege seu "maternar", tudo isso fundamentado nos conhecimentos femininos ligados à natureza. Pela maneira como o narrador apresenta essa mulher, conseguimos vislumbrar o conceito claro do ecofeminismo, vertente que acredita na integração do homem e da natureza, baseado no princípio que resgata a espiritualidade, valorizando o sagrado da vida de todos os seres que se encontram no cotidiano. Segundo Mies e Shiva (1993), o ecofeminismo deseja regenerar essa sabedoria, que foi desacreditada pela "ciência".

A quarta mulher é a que se permite e descobre "o amor em braços semelhantes aos seus". Nesse parágrafo, o narrador apresenta um relato delicado desse encontro, demonstrando num primeiro momento o estranhamento de Luamanda na nova descoberta e depois seu encantamento e encontro diante de sua igual que "dançou com leveza a dança- 
amor com ela", assim ela questiona quase como uma afirmação: "O amor se guarda só na ponta de um falo ou nasce também dos lábios vaginais de um coração de uma mulher para outra?", pois naquele momento saudade nenhuma ela sentiu de um homem de tão completadas foram todas "as fendas de seu corpo" pelas "femininas oferendas da outra".

O narrador apresenta a quinta mulher como uma amazona, substantivo feminino que podemos atribuir às mulheres que são corajosas por montarem em seus cavalos. No conto, o cavalo em que Luamanda está montada é um jovem moço encantado por “uma mulher que ele sabia madura". Momento em que há uma troca entre o jovem e ela, mas é Luamanda que se reencontra, se realimenta na juventude dele, na força e no seu vigor. A experiência amorosa com o jovem a faz renascer, interrogando se "o amor não cabe em um corpo?”.

Diferentemente da experiência narrada com o jovem que se apresenta viril e inocente para Luamanda, a sexta mulher, depois de muitos amores na vida, se apaixona avassaladoramente por um velho. Um amor mais lento, de um "falo adormecido, preguiçoso, sapiente de tanto corpos-histórias do passado", mas "foi no corpo do velho que ela melhor executou o ritual do amor”. A personagem encontra um amor calmo e cuidadoso - diante dessa experiência amorosa se vê na presença de um amor que é tempo de paciência.

A sétima face de Luamanda, em contraponto a sua vida de amor, vive a dor de um relacionamento ruim. Dor que passa a compor “as lembranças de seu caminho". Marcas que ela carregou pela vida feitas por um homem que não soube lidar com o fim de uma relação. Luamanda, assim como muitas mulheres, foi violentada, perfurada na sua vagina, parte tão viva do seu corpo. Ela, nesse tempo, ficou adormecida, precisou exercitar a paciência e convencer-se de que o prazer e o gozo retornariam e que era possível. A sétima mulher é a representação identitária de muitas mulheres brasileiras que diariamente sofrem violência de diversos tipos de seus parceiros e seguem sem proteção.

Um aspecto do texto que não podemos deixar de destacar é que a "lua" aparece em muitos momentos na narrativa desse conto. Ressaltamos que a lua na mitologia é a representação do feminino, vemos, assim, que a ela rege e está presente no nome escolhido para 
a personagem e na condução de sua vida. Ao longo do texto, verificamos que, muitas vezes, ela representa o olhar do narrador sobre Luamanda, guiando sua feminilidade e regendo a sua vida. Dessa forma, destacamos alguns trechos que ilustram essa observação: “[...] Era a lua mostrar-se no céu, Luamanda na terra se desmilinguia todinha” (p. 59); "A lua espiava no céu denunciando com a luz..." (p. 60); "Lua cúmplice da barrigas-luas de Luamanda" (EVARISTO, 2016, p. 61).

Luamanda é uma personagem, assim como a lua, que exerce encantamento, e é composta de mistérios.

É interessante observar no texto, o que precisaria de uma análise mais apurada, a criação, por Evaristo, de muitos neologismos, na tentativa de dar à palavra a dimensão necessária do sentimento que move Luamanda. Num olhar rápido, veremos que até no próprio nome Luamanda podemos inferir que é composto por "lua" (substantivo feminino) + manda (verbo no presente), podendo, como uma possibilidade, significar que a lua rege a vida.

Merece destaque, entretanto, que se a personagem não teme a alusão à lua e aos mistérios como símbolos de uma possível feminilidade (e desse modo reproduz o que o olhar masculino sempre viu nas mulheres. Mistérios perigosos, como uma certa personagem de olhos oblíquos de Machado), por outro lado, não se mantém como objeto estático de observação e perplexidade de um outro (o masculino). A personagem faz do seu corpo suas regras, ao gosto feminista, e toma a vida pelas mãos. Dessa maneira, pode revisitar a feminilidade tecida no patriarcado, como num essencialismo estratégico, no qual toma-se um conceito apropriado como natural para revelar sua construção até desconstruí-lo. Segundo nos ensina a Psicanálise: repetir até não precisar mais repetir.

Por fim, a Luamanda do presente descobre que está em aprendizado constante, que diante de todos os amores vividos “ainda lhe faltava testes, arguições e sabatinas" e que ela nada ou pouco sabia. Assim, o conto termina com ela se apressando para o encontro de um novo amor que talvez "já não suportasse um tempo de longa espera". 


\section{Luamanda(s)}

Ao se olhar no espelho, como se buscando a própria face, Luamanda mostra-nos sete faces construídas ao longo de cinco décadas. Podemos reconhecer nela que, como mulheres, somos muitas e distintas, somos compostas por essa diversidade, pois muitas mulheres habitam também nosso corpo de "alma-menina no tempo". Esse reconhecimento é muito importante para a valorização da literatura e escrita feminina.

A personagem construída por Evaristo é composta por no mínimo sete mulheres: a menina, a adolescente, a mãe, a bissexual, a madura, a companheira e a avó. Vimos que todas elas eram donas dos seus corpos, dos seus desejos e livres, ao romper padrões préestabelecidos pelo patriarcado do que é ser mulher. Constituída por muitas, ela era única, feminina, livre, fora dos padrões normativos, de alma jovem e que vive a vida liberta, sempre atendendo seus desejos e amores. Dona de si. Ao contar-se, inventa-se, cria-se, tornase, afinal ninguém nasce mulher.

Luamanda demonstra uma liberdade de escolhas no campo afetivo, uma liberdade que nos é negada pelas expectativas sociais de como deve se portar uma mulher, sobretudo no sexo. Permitindo-se viver e experimentar, não escapou das violências normalmente enfrentadas pelas mulheres da realidade, às quais o conto faz referência. Entretanto, apesar das dores, o temperamento confiante faz da personagem alguém que supera a realidade imposta. Conforme podemos verificar no trecho extraído do conto:

[...] Foi um tempo em que precisou exercitar a paciência com o seu próprio corpo. Trancada em si, ou melhor, aberta para si mesmo, com as mãos espalmadas e leves imaginava lenitivos carinhos. Chorando alisava, bulia, contornava uma cicatriz que ficara desenhada em um ponto da pele, onde os pelos se rarearam para sempre. Era um ponto único, minúsculo, um impertinente calombo. Ali, então alisava a dor e seus contornos. Era preciso convencer-se na sua floresta espessa e negra de que o prazer era uma via retornável, de que o gozo ainda era possível. O amor comporta variantes sentimentos? (EVARISTO, 2016, p. 63) 
A criação de uma personagem como Luamanda é de grande relevância para a reconstrução da identidade da mulher e mais ainda da mulher negra. É a tentativa de desconstrução da imagem hipersexualizada destinada às mulheres negras feita pela tradição literária brasileira. Ela sai do lugar de objeto de desejo para ser alguém que deseja.

Sendo assim, lançar a luz da crítica feminista sobre este texto e reconhecer a diversidade de mulheres existentes nele significa poder despertar um olhar para as tensões e contradições que permeiam a nossa cultura e, principalmente, uma tentativa de criar uma nova possibilidade, já que os olhos de muitos estão sombreados pela cultura impregnada do patriarcado.

Afinal quem somos e quem podemos ser? O que nos irmana em nossa mulheridade, aquilo que nos enlaça em pertença e que por mais que sejamos diversas ainda assim temos em comum.

Todos os dias, ao nos levantarmos, nos recriamos, pois somos muitas Luamandas, somos inúmeras e precisamos de muita força para lutarmos pela igualdade de gênero sem a prescrição de como devemos ser impostas diariamente pela sociedade em que estamos inseridas.

\title{
LUAMANDA AND HER “SEVEN FACES": AN ESSAY ON THE SHORT STORY "LUAMANDA", BY CONCEIÇÃO EVARISTO
}

\begin{abstract}
Luamanda, one of the short stories of Conceição Evaristo's book Olhos D'água (2016), shows a reflection about representations of feminine identities in patriarchy, now through a feminine writer's voice. It's not easy to live postmodernity in Brasil. In this context, Literature and literary critic becomes a balm. If Literature is considered as a "gender tecnology" locus (a place were women are brought up) and we suggest feminine readings for literatary works, we assume that it's necessary and urgent for women support Feminism. That is, this essay admits the importance of Feminism as a school that teaches a way of perceiving world. Thus, our suggestion of reading sees Luamanda's love experiences as the "seven faces" of the same woman, showing the composition and construction of womanliness through her lived and revisited experiences ("escrevivências"). So, through a feminist critic, this essay objetifies to investigate how many women there are in Luamanda.
\end{abstract}

KEYWORD: Literature. Woman/Women. Feminism. Feminine identity. 


\section{REFERÊNCIAS}

ADICHIE, Chimamanda Ngozi. Sejamos todos feministas/ Chimamanda Ngozi Adichie; tradução Christina Baum.1 ${ }^{\circ}$ ed. - São Paulo: Companhia das Letras, 2015.

BARBOSA, Adriana Maria de Abreu. Ficções do Feminismo. Vitória da Conquista - Bahia. Edições UESB, 2011.

BONNICI, Thomas. Teoria e Crítica Literária feminista: conceitos e tendências. Maringá: Eduem, 2007.

BEAUVOIR, Simone. O segundo sexo: fatos e mitos. São Paulo: Difusão Europeia do Livro, 1960 a.

BEAUVOIR, Simone. O segundo sexo: a experiência vivida. São Paulo: Difusão Europeia do Livro, $1960 \mathrm{~b}$.

EVARISTO, Conceição. "Conceição Evaristo: 'minha escrita é contaminada pela condição de mulher negra”. Nexo Jornal: 26 Mai 2017. Entrevista concedida a Juliana Domingos de Lima. Disponível em: < https://www.nexojornal.com.br/entre-

vista $/ 2017 / 05 / 26 /$ Concei $\% C 3 \%$ A7 $\%$ C3\%A3o-Evaristo- $\% E 2 \% 80 \% 98$ minha-escrita$\%$ C3\%A9-contaminada-pela-condi $\%$ C3 $\%$ A $7 \%$ C3\%A3o-de-mulher-negra $\% \mathrm{E} 2 \% 80 \% 99$ >. Acesso em: 20 de dezembro de 2018.

EVARISTO, Conceição. Da grafia-desenho de Minha Mãe, um dos lugares de nascimento de minha escrita. In: Representações performáticas brasileiras: teorias, práticas e suas interfaces. Belo Horizonte: Mazza, 2007. p. 16-21.

CÔRTES, Cristiane. Diálogos sobre escrevivência e silêncio. In: DUARTE, Constância Lima; CÔRTES, Cristiane; PEREIRA, Maria do Rosário A. (Orgs.) Escrevivências: identidade, gênero e violência na obra de Conceição Evaristo. Belo Horizonte: Idea, 2016. p. 51-60.

LAURETIS, Tereza de. A tecnologia do gênero. Indiana: University Press, 1987. Disponível em: < http://pt.scribd.com/doc/81873993/A-Tecnologia-do-Genero-Teresa-de-Lauretis $>$. Acesso em: 20 de março de 2019.

MIES, Maria; SHIVA, Vandana. Ecofeminismo. Lisboa: Instituto Piaget, 1993. p. 9-34.

MURARO, Rose Marie. Um mundo novo em gestação. Campinas: Verus editora, 2003.

RAGO, Luzia Margareth. A aventura de contar-se: feminismos, escritas de si e invenções da subjetividade. Campinas, SP: Editora da Unicamp, 2013. p. 13-59.

SANTIAGO, Ana Rita. (Re)existências e o devir revolucionário na literatura negro-feminina. fólio Revista de Letras, [S.1.], v. 10, n. 2, fev. 2019. p. 11-33. Disponível em: < http://periodicos2.uesb.br/index.php/folio/article/view/4702>. Acesso em: 29 jun. 2019. 
SILVA, Assunção de Maria Sousa e. Conceição evaristo e karol conka: a pulsão da palavra. fólio - Revista de Letras, [S.1.], v. 10, n. 2, fev. 2019. p. 59-72. Disponível em: <http://periodicos2.uesb.br/index.php/folio/article/view/4775>. Acesso em: 29 jun. 2019.

WOOLF, Virginia. Profissões para mulheres e outros artigos feministas. Porto Alegre, RS: L\&PM, 2013.

Recebido em: 30/05/2019. Aprovado em: 26/07/2019. 